\title{
The role of indigenous knowledge in computer education in Africa
}

\author{
Lorenzo Dalvit $^{1}$, Sarah Murray ${ }^{2}$ and Alfredo Terzoli ${ }^{3}$ \\ ${ }^{1}$ SANTED programme, School of Languages, Rhodes University, PO Box \\ 94, 6140 Grahamstown South Africa. 1.dalvit@ru.ac.za, \\ http://www.ru.ac.za/academic/departments/languages/santed/people.html \\ ${ }^{2}$ Education Department, Rhodes University, PO Box 94, 6140 \\ Grahamstown South Africa. s.murray@ru.ac.za, \\ http://campus.ru.ac.za/index.php?action=category\&category=1275 \\ ${ }^{3}$ Telkom Centre of Excellence, Computer Science Department, Rhodes \\ Unviersity, PO Box 94, 6140 Grahamstown South Africa. \\ a.terzoli@ru.ac.za, \\ http://cs.ru.ac.za/people/staff.php
}

\begin{abstract}
The integration of indigenous knowledge/languages in formal education is a contentious issue in post-colonial Africa. For historical and economic reasons, these are devalued in the formal education system. We argue that appropriate use of indigenous knowledge/languages can empower African students academically even in typically "Western" disciplines, such as Computer Science. We discuss the potential role of indigenous languages/ knowledge in ICT education and then describe an intervention, supporting students from marginalised communities, at a South African University.
\end{abstract}

\section{Introduction}

Computer Science promises much too prospective students in Africa: it is potentially empowering both economically and in terms of global access. However, since most computer-related knowledge is produced and consumed in the West, and conceptualised in European languages, it inevitably reflects Western assumptions and ways of thinking. This makes it a difficult subject of study for many African students who, besides having difficulties in accessing the necessary infrastructure, are also unfamiliar with the paradigms informing the discipline. Integrating African indigenous knowledge into the teaching of Computer Science may help to bridge this gap. This, however, needs to be problematised in order to define the role and boundaries within which such integration might benefit African students. 


\section{Indigenous knowledge}

Indigenous knowledge literally means "knowledge that is specific to one place". In this sense, all knowledge can be considered indigenous in so far as it pertains to a particular geographical location. The term "indigenous", however, is often associated with something exotic and "other", often in a pejorative sense. Western knowledge is usually taken as the reference point for the comparison and the norm against which whatever is indigenous is understood and possibly evaluated [1]. For the purpose of this paper we consider indigenous knowledge as having 3 components: traditional, common and specialised knowledge.

\subsection{Traditional knowledge}

Traditional knowledge is what, in layman's terms, most people refer to as indigenous knowledge. It is often associated with the religious, spiritual or occult sphere, and is validated by having been part of a specific culture for a long time. Some forms of traditional knowledge, such as those relating to Christianity, have been integrated into formal education, for example, under Apartheid Christian National Education in South Africa. However, African traditional knowledge and, particularly, African religious beliefs were deliberately opposed by missionary education in an attempt to assimilate or integrate the local population [2]. This probably contributed to the stigma attached to indigenous knowledge as a whole. ICT education, with its emphasis on modernity, is often understood in opposition to traditional values and beliefs, be they Western or African.

\subsection{Common knowledge}

Common knowledge refers to "what everybody knows" and concerns every sphere of daily life. Examples, such as the ones from the health sphere for instance, show how common knowledge is not always scientifically sound and could, in some extreme cases, have dramatic consequences. However, common knowledge is an integral part of the cultural background of a community and as such it should be taken into account by educators. It may be integrated into the curriculum, providing useful examples and metaphors to support teaching. In other cases common knowledge needs to be de-constructed and critically analysed [1]. The inclusion of common knowledge in the curriculum is contentious in Science education, where it may often contradict scientific knowledge.

\subsection{Specialised knowledge}

Specialised knowledge is specific to a particular field, and is usually possessed by "experts". The boundaries between common and specialised knowledge can be blurred by time and space. While being able to operate a computer through the Graphical User Interface (GUI) can be considered common knowledge among middle class, urban youth in developed countries, it was specialised knowledge until a few years ago and is still so in many parts of most developing countries. 
The GUI example also highlights a relationship between specialised and common knowledge. The desktop environment, which contains folders and files and can be browsed through windows, draws on the metaphor of an office desk. For most middle class youth, offices are part of their common knowledge that can be drawn upon when learning to operate a computer through the GUI. For those in developing countries, however, the metaphor may be meaningless [3].

There are other culturally-bound conventions and traits which are taken for granted in the ICT world, such as colour schemes and language. In most Western cultures, for instance, red indicates "danger" or "stop", as opposed to green, which signifies "go ahead". In various African cultures, however, red is the colour associated with tradition, as opposed to blue which symbolises modernity. Likewise, English, the language used in the field of ICT, is not widely spoken or understood by the majority of rural Africans. The lack of terminology in African languages (and the current efforts to develop it [4]) could be seen as marking the still incomplete transition of digital literacy from specialised to common knowledge among their speakers. Within the realm of common knowledge, differences that are important in English (e.g. the one between a menu and a list) are not reflected in many African languages (e.g. in isiXhosa, uludwe means both menu and list).

\section{Indigenous knowledge and ICT education}

The differences mentioned above clearly put African students at a disadvantage when they encounter computers, as they cannot draw on their common knowledge in the way Europeans (and particularly English speakers) do. However, the role of common knowledge in scientific education is the subject of debate. Some scholars have argued that the purpose of education is to replace common knowledge with (Western) specialised knowledge. Two scholars in particular, the Italian philosopher, Gramsci, and the British linguist, Halliday, point to inherent dangers of adopting a relativist position with regard to common knowledge; we take account of their arguments below. In our response to their concerns we also refer to the field of ethnocomputing.

\subsection{Gramsci - the role of common knowledge in maintaining hegemony}

Gramsci argued that education is the primary tool for the reproduction of inequality in society [5]. In his view, common knowledge (or "folklore") kept people in ignorance and thus in their place. He called for education to take the moral responsibility of combating folklore and substituting it with "higher" (i.e. specialised) knowledge that would make people's social positioning visible to them [6].

Apartheid South Africa offered a striking example of hegemony at work through education. Education for blacks (Bantu Education) made extensive use of indigenous languages and knowledge in the curriculum in order to relegate Africans to an idealised and ideologically constructed African past and deny them active participation in the global community [7]. This was based on a static and "purist" 
understanding of culture and, as a consequence, of indigenous knowledge. This continues in post-colonial African education, where the dichotomy between traditional (African) knowledge and modern (Western) knowledge is enforced as a clear-cut choice between holding on to tradition and embracing formal education. This does not reflect either the modern understanding of culture and knowledge as dynamic or the bi-cultural and bi-lingual reality of most African students. In this sense, giving African students access only to Western specialised knowledge disempowers them twice. From the educational point of view, they do not have the scaffolding provided to Western students by their common knowledge. From the ideological point of view, their own traditional, specialised and, to some extent, common knowledge is denied formal recognition within the education system.

\subsection{Halliday - Functional linguistics}

Functional linguists [8] discuss the specific features of scientific discourse in the domain of education. Science education consists mainly of unpacking technical terms and constructing new classifications to replace existing, commonsensical ones. Halliday and Martin [8] emphasise the creative character of science education and openly criticise the practice of trying to reduce "scientific language" to "common language" in the classroom.

In an African post-colonial context, however, the relationship between scientific and everyday language is often nested within a diglossic situation. For many African students English, which is the language of scientific discourse, is a second or foreign language while everyday communication takes place in one or more indigenous African languages. Given the strong link between language, culture and knowledge, this can be considered as representative of the multi-cultural reality of many African students, who live the tension between tradition and modernity. This is particularly evident in the teaching of scientific and technological subjects which, having been developed within the Western paradigm, are foreign to African culture. For example, while philosophical concepts such as that of ubuntu can readily be integrated into Western academic discourse within the Humanities as representing an alternative paradigm [9], indigenous taxonomies for diseases, must be de-constructed and substituted with new ones within the Western scientific discourse.

In Mathematics education, teachers in African schools often code-switch between the dominant European language (often English) and the local African language. New English technical terms are introduced and explained in the students' mother tongue with examples from their everyday lives. The mathematical discourse is then reconstructed in English, which is the only language of testing. Within this model, two aspects seem to be problematic. Firstly, for many African students formal education is the only domain where they are exposed to the powerful Western epistemological paradigm and European languages. Mastery of both is what will determine their opportunities for employment later in life. For this reason, teachers feel the need to expose students as much as possible to these powerful tools in the little time they have available in the classroom.

In South Africa, code-switching is the norm in African schools. This could not be otherwise, given the generally low English proficiency of most African students [10]. 
However, despite progressive policies nothing has been done to formalise multilingual teaching. Thus, every teacher has to "re-invent the wheel", creating his or her own new terminology and examples. This has two sets of consequences. Pedagogically, it is an inefficient way of organising a process that is so widespread and potentially has such a huge impact on the education system.

Ideologically, it entrenches Western hegemony by reproducing the dichotomy between two paradigms of knowledge. On the one hand, Western specialised knowledge draws on Western common knowledge in a structured and organised way through textbooks and other teaching material. On the other hand, individual teachers draw on African indigenous knowledge, whether it is specialised or common, in a haphazard and ad hoc manner. This reinforces the idea, in the mind of the students, that the Western paradigm is indeed superior and Africa has little to offer in terms of knowledge to the global community.

\subsection{Ethnocomputing}

Ethnocomputing emphasises the importance of integrating cultural elements into software design and the teaching of Computer Science in developing countries [11]. Since computers were invented in the West, they tend to reflect Western values and cultural traits, thus promoting dependency. To counter dependency, the use and teaching of computers must integrate indigenous knowledge and respond to local problems, making technology more relevant and more accessible at the same time.

Duveskog et al [12] provide a practical example, based on their experience in Tanzania, of how the use of fractals in traditional art craft could be used to support the teaching of recursion in the teaching of Computer Science. On a different level, the African philosophical concept of ubuntu has named one of the most popular Linux distributions. Ubuntu, which literally means "humanity" in isiXhosa and isiZulu, encompasses values of sharing and emphasises the interdependency between all human beings. It therefore captures the spirit of much of the open-source community more precisely than comparable Western terms.

Advocates of ethnocomputing argue that individuals in developing countries need to be given access to meaningful study of how computers work. Like Gramsci's organic intellectuals, they would combine sufficient knowledge of the local context and mastery of the discipline, supporting the development of alternative discourses. However, such individuals are hard to come by, since most Africans with access to ICT (like any other powerful field of study) are usually part of the emerging elite and have internalised Western values and world-views.

\section{Intervention}

In the last section of our paper we describe an intervention, informed by the considerations above, to integrate African indigenous knowledge in the teaching of Computer Science [13]. Material has been developed and tested at Rhodes University, a Historically White South African institution. Like many other South African universities, Rhodes is under pressure from the government to provide 
access to economically empowering fields of study to members of marginalised communities. In particular, the development of previously marginalised areas and communities requires African graduates and postgraduates in Computer Science who can address local needs [14].

\subsection{Focus group}

Rhodes provides alternative access to members of marginalised communities through its Extended Studies Programme (ESP). The programme targets mainly African students from underprivileged schools. In most cases, these are first-generation university students who are neither very proficient in English nor fully familiar with Western culture. Most of them are speakers of isiXhosa, the locally dominant African language.

Our intervention focused on the Computer Skills component of the programme. Classes were relatively small (20-30 students) and students used computers both in practicals and in lectures, allowing for the use of a web-based application that supported the integration of indigenous knowledge/languages in teaching practice.

\subsection{Material}

The material we developed consisted of a glossary of computer terms translated, explained and exemplified in isiXhosa. The development of the material was done collaboratively by a group of experts (mainly isiXhosa speakers) from various disciplines, ranging from computer science to education and linguistics. In an African spirit, the material was developed during long meetings where each term was discussed and people with different levels of computer literacy had a chance to express their views. Team members were representative of the full spectrum of different realities within the Xhosa community, allowing us to capture some of the variety of Xhosa indigenous knowledge.

Each computer term was translated into an isiXhosa equivalent as suggestive as the English one is to a native speaker. The word wizard, for instance, was translated as umvumisi, a type of traditional healer who asks the patient questions in order to diagnose the cause of a disease. Thus, the term suggests what a wizard does (i.e. guiding the user through a series of steps to achieve something). Each term is then explained and exemplified drawing on the students' knowledge. For example, the relationship between a client and a server is compared to that between a bride and the person designated to assist and equip her for the wedding (umxobisi).

The glossary currently comprises more than 150 terms, and is growing. It is available both in print and on-line, and in both versions, related terms are highlighted and linked to show relationships between concepts and build classifications. Students were given access to the glossary at the beginning of 2007 and encouraged to participate in its development with comments and feedback. 


\subsection{On-line resource}

The on-line version of the glossary was integrated into the e-learning course students used in class. Moodle, the Learning Management system used by Rhodes, has a glossary module which was marginally "tweaked" to serve research purposes. This avoided the problem of burdening students who were not familiar with ICT with an additional and unfamiliar on-line resource. Alongside the copy used in the course, the glossary was also made available standalone (see http://www.isixhosa.ru.ac.za).

Moodle allows for numerous interactions between the users and the system. Standard glossary features allowed students to rate entries and give comments. Words which appeared in the explanation and were included in the glossary were hyperlinked, making it easy to follow the relationships between different concepts. System logs allowed us to monitor the use of the resource to see which terms were most popular and which words that students looked for were not in the glossary, so that they could be developed and included.

The on-line glossary is currently being integrated with multimedia. Besides the obvious advantages of using images and video tutorials to integrate text-based material, the use of audio explanations is culturally more appropriate for students from a predominantly oral culture, who may be unfamiliar with the written variety of their mother tongue [10]. The content of the glossary is also being visualised through a concept map using CMapTools, adding a further visual component to explanations, highlighting relationships between concepts and clarifying taxonomies.

\section{Conclusions}

As we have shown, in the post-colonial African context, local indigenous knowledge is attributed low status and excluded from formal education, disempowering African students educationally and ideologically, by devaluing their knowledge and entrenching Western epistemological hegemony.

Particularly in science and technology education, students' common knowledge must be de-constructed and new concepts and taxonomies created. The function of indigenous knowledge is to support and integrate access to global knowledge, and not to relegate students to marginalised local realities. Furthermore, common knowledge, whether it be Western or African, must be integrated carefully in highquality teaching and educational material. In the case of Computer Science, this would contribute to the development of programmers who share the background of the majority of the local community and can develop appropriate solutions for local problems.

Our intervention focused precisely on this kind of student. Material in the locally dominant language, using culturally appropriate metaphors and examples, was used to support an existing Computer Skills course. The material was shaped by students through feedback and suggestions. The use of an on-line resource allowed for the integration of multimedia, a medium more appropriate to the cultural background of most students. A preliminary evaluation suggests that the intervention boosted students' confidence in the potential of their own language and indigenous 
knowledge to help them academically. More conclusive results will be available by the time of the conference.

\section{References}

1.Agrawal, A. Indigenous and scientific knowledge: some critical comments, Indigenous Knowledge and Development Monitor 3(3), 3-6, 1995

2.Okere, T., Njoku, C.A., and Devisch, R. All knowledge is first of all local knowledge: an introduction, Africa Development 30(3), 1-19, 2005

3.Thinyane, M., Dalvit, L., and Terzoli, A. The Internet in Rural Communities: Unrestricted and Contextualised. Submitted for ICT Africa, Addis Abeba, 13-15 February 2008

4.Finlayson, R. and Madiba, M. The Intellectualisation of the Indigenous Languages of South Africa: Challenges and Prospects. Current Issues in Language Planning, 3(1), Multilingual Matters, 40-61,2002

5.Borg, C., Buttigieg, J.A., and Mayo, P. Gramsci and Education, Rowman \& Littlefield Publishers, 2002

6.Gramsci, A., Hoare, Q., and Nowell-Smith, G. Selections from the Prison Notebooks, Electric Book Company, 2005

7.Kamwangamalu, N.M. The Language Planning Situation in South Africa, Language Planning and Policy in Europe, Multilingual Matters, 2006

8.Halliday, MAK, and Martin, JR: Writing science: Literacy and discursive power. Pittsburgh, PA: University of Pittsburgh Press, 1993

9.Kamwangamalu, N.M. Ubuntu in South Africa: a sociolinguistic perspective to a pan-African concept, Critical Arts 13(2), Routledge, 24-41, 1999

10.Heugh, K., and Project for the Study of Alternative Education in South Africa: The Case Against Bilingual and Multilingual Education in South Africa, PRAESA, 2000

11.Tedre, M., Sutinen, E., Kähkönen, E., and Kommers, P. Ethnocomputing: ICT in cultural and social context, Communications of the ACM 49(1), ACM Press New York, NY, USA, 126-130, 2006

12.Duveskog, M., Sutinen, E., Tedre, M., and Vesisenaho, M. In search of contextual teaching of programming in a Tanzanian secondary school, IEEE conference Frontiers in Education (FIE) 2003, 5-8, 2003

13.Dalvit, L., Murray, S., Mini, B., Terzoli, A. \& Zhao, X.. Production of and Access to ICT-Based Knowledge through English and African Languages at a South African University. South African Journal of Higher Education (SAJHE), 19, 1486 - 1498, 2006

14.Department of Education (DoE) and Department of Communication (Doc): Strategy for Information and Communication Technology in Education. Pretoria: Government Printer. 